\title{
O POTENCIAL DA AÇÃO PÚBLICA NO PROCESSO DE RECONEXÃO ENTRE AGRICULTURA, ALIMENTAÇÃO, MEIO AMBIENTE E SAÚDE NO ÂMBITO TERRITORIAL
}

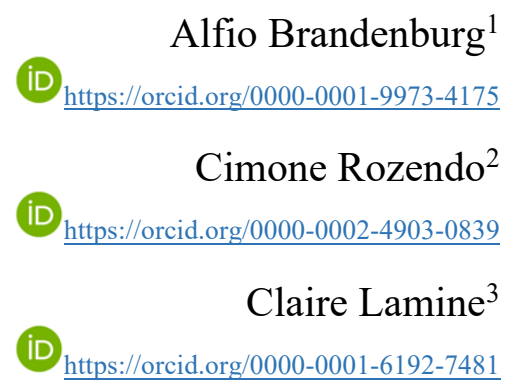

\section{RESUMO}

Este artigo tem por objetivo analisar o papel da ação pública na reconexão entre agricultura, alimentação, meio ambiente e saúde, no âmbito de três territórios (Apodi, no Nordeste do Brasil; Assentamento Contestado, na Lapa, Sul do Brasil; e Ardèche, na França). Trata-se de uma revisão bibliográfica inspirada na abordagem da sociologia pragmática. Constatou-se que a agroecologia exerce um papel articulador na reconexão em diferentes graus e que essa é potencializada por iniciativas locais e por políticas públicas.

Palavras-chaves: Reconexão Ambiental, Ação Pública, Agroecologia, Território.

\section{THE POTENTIAL OF PUBLIC ACTION IN THE PROCESS OF RECONNECTING AGRICULTURE, FOOD, ENVIRONMENT AND HEALTH AT THE TERRITORIAL LEVEL}

\section{ABSTRACT}

This article aims to analyze the role of public action in the reconnection between agriculture, food, environment and health within three territories (Apodi, in Northeastern Brazil; Contestado Settlement in Lapa, Southern Brazil; and Ardèche, in France). This is a literature review inspired by the pragmatic sociology approach. It was found that agroecology plays an articulating role in the reconnection in different degrees and that this is enhanced by local initiatives and by public policies.

Keywords: Environmental Reconnection, Public Action, Agroecology, Territory.

\section{EL POTENCIAL DE LA ACCIÓN PÚBLICA EN EL PROCESO DE RECONEXIÓN DE LA AGRICULTURA, LA ALIMENTACIÓN, EL MEDIO AMBIENTE Y LA SALUD A NIVEL TERRITORIAL}

\section{RESUMEN}

Este artículo tiene como objetivo analizar el papel de la acción pública en la reconexión entre agricultura, alimentación, medio ambiente y salud en tres territorios (Apodi, en el noreste de Brasil; asentamiento de Contestado en Lapa, sur de Brasil; y Ardèche, en Francia). Esta es una revisión de la literatura inspirada en el enfoque de la sociología pragmática. Se encontró que la agroecología

\footnotetext{
${ }^{1}$ Doutor em Ciências Sociais. Docente do Programa de Pós-Graduação em Sociologia e do Doutorado em Meio Ambiente e Desenvolvimento da Universidade Federal do Paraná. E-mail: alfiob@hotmail.com.br.

${ }^{2}$ Doutora em Meio Ambiente e Desenvolvimento. Docente do Departamento de Ciências Sociais da Universidade Federal do Rio Grande do Norte e dos Programas de Pós-Graduação em Ciências Sociais e Desenvolvimento e Meio Ambiente. E-mail: cimone.rozendo@gmail.com.

${ }^{3}$ Doutora em Sociologia. Pesquisadora do Institut National de Recherches Agronomiques (INRA), na França. E-mail: claire.lamine@inrae.fr.
} 
juega un papel articulador en la reconexión en diferentes grados y que esta es potenciada por iniciativas locales y por políticas públicas.

Palabras claves: Reconexión Ambiental, Acción Pública, Agroecología, Territorio.

\section{INTRODUÇÃO}

Este texto resulta do projeto "Transição agroecológica dos sistemas agroalimentares no Brasil e na França", no âmbito do acordo CAPES/COFECUB, que analisa o processo de articulação, agricultura, alimentação, ambiente e saúde em diferentes territórios. Partimos do pressuposto de que a reestruturação dos sistemas agroalimentares mundializados, por intermédio de longas cadeias, ocasionaram a desconexão, em múltiplos níveis, entre as esferas produtivas, de beneficiamento e de consumo, conformando verdadeiros impérios agroalimentares (Ploeg, 2008). Desta maneira, a lógica dos sistemas locais foi desarticulada e os alimentos perderam os vínculos sociais e ambientais com seus territórios e seus produtores. Processo esse denominado na literatura de desconexão (Renting; Marsden; Banks, 2017; Goodman, 2017); além disso, a produção de autoconsumo foi secundarizada, deixando os agricultores e os camponeses cada vez mais dependentes dos recursos externos à sua unidade produtiva, os saberes tradicionais foram desvalorizados e a diversificação da produção deu lugar à especialização. Em um sentido mais amplo, o ambiente de produção se tornou cada vez mais artificializado, perdendo sua sustentação natural, e as condições de vida dos agentes produtores se deterioraram.

Nesse contexto de transformação social e produtiva e de mudança escalar do sistema, concebido aqui como um processo de desconexão, subjaz uma reestruturação de territórios ecossociais. Se, por um lado, os territórios de cultivo de alimentos são submetidos à lógica hegemônica dos sistemas agroalimentares mundializados, por outro, por força dos movimentos sociais e políticas públicas recentes, são construídos sistemas agroalimentares alternativos em que a agroecologia exerce um papel articulador entre a agricultura, a alimentação, o meio ambiente e a saúde, com vistas a reconectar produção, beneficiamento e consumo. Podemos, assim, afirmar que essas duas lógicas coexistem na forma de tensões e de disputas sociopolíticas, mas também na forma de interrelação, contribuindo para a transição agroecológica. Contribuem para isso: a força do Estado via políticas públicas e de fomento; as ações coletivas locais, que respondem a conjunturas de movimentos políticos; a força do mercado, que, por sua lógica organizacional, impõe uma racionalidade econômica e instrumental "fagocitadora" das racionalidades plurais; e a força social da sociedade civil, por meio dos movimentos organizados que reivindicam formas alternativas de organização social e produtiva.

Interessa-nos analisar, pois, neste trabalho, o papel que a ação pública desempenha na reconexão ou desconexão entre a agricultura, a alimentação, o meio ambiente e a saúde, no âmbito 
territorial. Isto é, de um lado, focar na ação do Estado e nas políticas públicas formuladas em períodos recentes; de outro, considerar os projetos alternativos de cunho ecológico, as iniciativas locais e as ações coletivas que emergem a partir de agentes, movimentos e organizações locais, visando transformar o sistema agroalimentar na perspectiva da transição agroecológica. Em resumo, temos como objetivo analisar o potencial da ação pública nas diferentes formas de reconexão ou desconexão, no âmbito de três territórios: o município de Apodi, no estado do Rio Grande do Norte, região Nordeste do Brasil; no Assentamento do Contestado, na Lapa, na região Sul do Brasil; e o território de Ardèche, na França.

A partir da bibliografia disponível sobre esses territórios, buscamos reconstituir a trajetória dos seus sistemas agroalimentares, destacando o papel da ação pública nos distintos processos de reconexão ou desconexão, em especial de 1985 a 2015. Essa abordagem aproxima-se de uma perspectiva da sociologia pragmática ${ }^{4}$, conforme Lamine et al. (2015). Diversos trabalhos analisaram a conexão ou a desconexão dos sistemas alimentares, considerando os efeitos sobre as esferas produtivas, de beneficiamento e consumo (Renting; Marsden; Banks, 2017; Goodman, 2017). Em cada uma delas, podemos identificar uma miríade de pequenos rearranjos (Vendruscolo et al., 2018; Piraux; Cuenin, 2019), com potencial sinérgico e transformativo, explorados de modo ainda insuficiente. Nossa proposta é aprofundar esses aspectos destacando as múltiplas formas de expressão desta reconexão nos territórios estudados e o papel da ação pública nesse processo.

\section{APODI E AS FORMAS DE RE-EXISTÊNCIAS NA CONSTRUÇÃO DE UM TERRITÓRIO SUSTENTÁVEL}

O município de Apodi situa-se no estado do Rio Grande do Norte e faz parte da região semiárida do Nordeste brasileiro. Devido à sua localização, acaba sofrendo com períodos de estiagem e secas prolongadas. Seu território tem uma área de $1.602 .480 \mathrm{~km}^{2}$ e uma população de 34.763 habitantes, sendo 49,57\% rural, e 50,43\% urbana, com densidade populacional de 22,50 habitantes por $\mathrm{km}^{2}$ (IBGE, 2010). Apesar do Índice de Desenvolvimento Humano (IDH) de 0,727, 30,3\% da população com 25 anos ou mais ainda é analfabeta (IPEA, 2013) e 27\% da população rural encontrase em situação de extrema pobreza (MDS, 2015), estando concentrada no espaço rural.

A agricultura familiar de base camponesa é a forma majoritária de organização social da produção no território. Dos 3.274 estabelecimentos existentes, 93\% são de agricultura familiar, conformando 94 comunidades rurais (IBGE, 2006) e 26 assentamentos de reforma agrária (MDS,

\footnotetext{
${ }^{4}$ A sociologia pragmática desenvolveu-se como uma sociologia da "crítica", face à sociologia crítica dominante nos anos 1990, baseada, em particular, na obra de L. Boltanski, F. Chateauraynaud e D. Céfaï. Coloca em primeiro plano o argumento dos atores para justificar suas escolhas de ação e comprometimento.
} 
2015). 48\% dessas comunidades têm áreas de até 10 hectares. Apodi possui uma organização social com forte incidência nos processos de transição agroecológica que buscam potencializar as formas latentes da agricultura camponesa presentes na região. As reflexões que seguem reconstituem a trajetória que fez de Apodi uma "referência regional e nacional na construção territorial popular da agroecologia, da convivência com o semiárido e das redes de economia solidária” (Santos, 2016, p. 54), destacando as ações que permitiram reconectar os sistemas alimentares locais, sempre considerando as dimensões da agricultura, da alimentação, do meio ambiente e da saúde, bem como os elementos que ameaçam esse movimento.

A construção das bases agroecológicas e o restabelecimento dos vínculos com a terra a partir da Reforma Agrária

A partir da década de 1960, a Igreja Católica, através dos Movimentos Eclesiais de Base (MEB), passou a estimular a organização dos trabalhadores rurais na região. O MEB constituía um dos poucos espaços de articulação política no contexto de ditadura civil e militar. Muitas dessas mobilizações se davam a partir de lutas pontuais, às quais outras pautas se somavam, à medida que os movimentos se fortaleciam. A abertura do primeiro poço coletivo ilustra isso. Após a iniciativa, constatou-se que, das cem famílias envolvidas, apenas 35\% possuíam terra, sendo que muitas delas nem sequer tinham sementes para cultivar. Criaram-se então os "bancos de sementes", um espaço comunitário onde os agricultores mantinham seus estoques de variedades nativas, podendo melhorálas, adaptá-las e trocá-las entre si. Tais iniciativas oportunizaram um processo contínuo de experimentações organizacionais e produtivas e criaram novos valores e necessidades, o que levou à constituição do Sindicato dos Trabalhadores Rurais (STR), na década de 1980 (MDA/PTDR, 2010), organização que se mostrou fundamental para os movimentos de luta pela terra que se estabeleceram na sequência.

O restabelecimento do regime democrático e a implantação do I Plano Nacional da Reforma Agrária, no ano de 1986, abriram espaço para o fortalecimento das reivindicações por reforma agrária, resultando na criação de 26 assentamentos com cerca de 650 famílias (MDA/PTDR, 2010), todas oriundas da região e formadas por filhos e filhas de agricultores locais, arrendatários e posseiros, trabalhadores das antigas fazendas produtoras de algodão e de extração de pedra. A política de reforma agrária reconfigurou o território de Apodi (Santos, 2016; Rozendo 2018) e restabeleceu os vínculos entre os agricultores e a terra. As ONGs de assistência técnica que passaram a operar na região contribuíram para a recomposição de um tecido social baseado no associativismo, na defesa da saúde, na importância da produção de alimentos para autoconsumo e na valorização dos saberes locais, aspectos que foram fundamentais para que Apodi se notabilizasse, a partir dos anos 2000, como um "território agroecológico" (Santos, 2016; MDA/PTDR, 2010). Na prática, o que havia de 
“agroecológico" era a promoção daquilo que era próprio das formas de reprodução da agricultura camponesa: a ampliação dos sistemas tradicionais de manejo da Caatinga; a produção animal e vegetal em consórcios; a manutenção de estoques de sementes nativas e/ou crioulas, etc. Muitas dessas iniciativas foram apoiadas pelas organizações religiosas (com suas redes internacionais), pelo STR e pelas universidades, com seus projetos de extensão, promovendo um intenso movimento de compartilhamento de experiências e produção de novos conhecimentos. Isso se fez sob uma forte narrativa de defesa da saúde e do meio ambiente, em um contexto de disseminação de projetos de fruticultura irrigada, financiados pelo Estado brasileiro, que já fazia suas vítimas em regiões circunvizinhas ao contaminar água e solo, ao ampliar as intoxicações por agrotóxicos e ao exterminar espécies da fauna e flora.

A criação do PRONAF (Programa Nacional da Agricultura Familiar), em 1996, embora marcadamente produtivista, foi outro fator importante para a reconexão do sistema alimentar local, garantindo financiamento à produção, inclusive à agroecológica. $\mathrm{O}$ fortalecimento da pecuária de caprinos, por exemplo, por sua natureza resiliente, permitiu algum grau de segurança econômica e alimentar à população sertaneja nos períodos de estiagem (Santos, 2016; Araújo et al, 2013) quando a produção de alimentos se escasseou e as rendas diminuíram. A criação da Articulação do Semiárido (ASA), no ano de 1999, foi, sem dúvida, um marcador importante de reconexão e de potencialização de estratégias agroecológicas (Santos; Rozendo; Diniz, 2019) consubstanciadas na proposição de um novo paradigma de desenvolvimento: a convivência com o semiárido - concebido como uma expressão "nativa" da agroecologia. ${ }^{5}$

A década de 1990 é apontada pelos estudos (MDS/PTDR, 2010; Santos, 2016; Rozendo, 2018; Nunes, 2011) como um período de grande aprendizagem coletiva e de potencialização das formas de agricultura camponesa, responsáveis pelo fortalecimento do tecido social que deu sustentação a inúmeros projetos de desenvolvimento rural com foco na saúde, no meio ambiente, na alimentação, na autonomia dos agricultores e agricultoras, que foram potencializados por um conjunto de políticas públicas a partir dos anos 2000. Essas ações articuladas às pautas das agendas globais, sobretudo à ambiental, ganharam impulso e visibilidade, constituindo uma força vigorosa para os projetos de transição agroecológica que se sucederam.

A sinergia entre as políticas públicas e as organizações sociais de Apodi no processo de transição agroecológica

Entre 2000 e 2004, consolidaram-se diversas associações, cooperativas e a feira da agricultura

\footnotetext{
${ }^{5}$ O Programa de convivência fundamenta-se em duas premissas: a conservação, uso sustentável e recomposição ambiental dos recursos naturais do semiárido; e a quebra do monopólio de acesso à terra, à água e a outros meios de produção (Declaração do Semiárido, 1999, p. 5).
} 
familiar no município, com o objetivo de comercializar a produção que vinha sendo fomentada. O histórico de mobilizações, conquistas e aprendizados coletivos envolvendo a sociedade civil e o Estado acabou por transformar Apodi em um território de experimentações de políticas públicas de diversas naturezas, ou seja, em uma espécie de "laboratório social" (Vieira, 2013; Rozendo, 2018; Nunes et al., 2013). A conformação de um cenário político nacional mais aderente às questões sociais com a eleição de Luiz Inácio Lula da Silva à presidência da República foi fundamental para isso. A centralidade dada à erradicação da pobreza e da fome na plataforma política contribuiu para ampliar projetos participativos com foco na agroecologia, na democratização do acesso à água, na agricultura familiar, reforçando assim o capital social e consolidando a convivência com o semiárido como diretriz para a ações na região.

Essa concepção já vinha orientando o Programa Dom Helder Câmara (PDHC) ${ }^{6}$, cujos projetos foram reconhecidos pelo seu protagonismo na potencialização da agroecologia no município, articulando as dimensões sociopolíticas, ambientais, culturais, econômicas e tecnológicas, e os processos participativos de planejamento, gestão e controle social. A abordagem territorial de desenvolvimento foi fundamental para que a região se tornasse uma referência em agroecologia (Santos, 2016). Na sequência, destacamos alguns projetos agroecológicos que buscaram reconectar produção, consumo e beneficiamento, evidenciando como as dimensões da agricultura, alimentação, saúde e meio ambiente se articularam nessas iniciativas.

A criação de Unidades Demonstrativas em Manejo da Caatinga, em várias comunidades do município (Santos, 2016; MDA/PTDR, 2010), representa uma estratégia pedagógica basilar no processo de transição agroecológica. São campos de experimentos da biodiversidade local construídos a partir dos saberes locais e da troca de experiências entre agricultores/as. Neles, associavam-se o plantio de milho, de feijão de sequeiro, a criação de animais e os chamados quintais produtivos com o cultivo de frutíferas, visando a ampliar a produção e a diversidade de produtos da pauta alimentar local. A produção excedente abastece o mercado local, em especial a Feira Agroecológica de Apodi. O projeto Experimentação em Hortas e Pomares Agroecológicos teve orientação semelhante e foi uma importante ferramenta na conversão agroecológica de áreas de produção de hortaliças e frutas. Ampliou o autoconsumo e abasteceu 15 unidades de beneficiamento de polpas, criadas pelas agricultoras. A produção foi comercializada pelas cooperativas, pelo Programa de Aquisição de Alimentos (PAA) e na feira agroecológica local (Gurgel, 2016; MDA/PTDR, 2010). Ela focou na recuperação de espécies tradicionais da região, como a cajarana, a goiaba, a castanha-de-caju; na participação de mulheres e jovens por meio do aprendizado coletivo,

\footnotetext{
${ }^{6}$ Foi um projeto do Ministério do Desenvolvimento Agrário, fruto do acordo com o Fundo Internacional de Desenvolvimento Agrícola (FIDA) e de doação do Fundo Mundial para o Meio Ambiente. Disponível em: $<$ http://www.projetodomhelder.gov.br/site/o-projeto-dom-helder/area-de-atuacao.html>. Acesso em:15.05.2015
} 
com intercâmbios nacionais e internacionais; na consolidação das estruturas de beneficiamento e no estabelecimento de redes de comercialização com parcerias em diferentes níveis. Essa iniciativa foi complementada pelo projeto de Bioágua Familiar, que reutiliza as águas cinzas das casas para irrigação da produção dos quintais. Nesses três casos, observamos a sinergia entre experiências expressas na capacidade de articular as dimensões da produção, do beneficiamento e do consumo, pautados no aprendizado coletivo, na preservação das culturas locais, na segurança alimentar, na preservação dos bens comuns e no protagonismo feminino.

A reconexão também pode ser identificada por meio do projeto das Casas de Sementes. Inspirada em práticas tradicionais dos sertanejos, a proposta foi encampada pela ASA em sua estratégia de convivência com o semiárido. O objetivo foi conservar as "sementes crioulas" por meio do armazenamento e da sua troca entre os agricultores/as, com o intuito de garantir: a reprodução de variedades adaptadas à região; a segurança alimentar; e a autonomia dos camponeses em relação ao mercado de sementes. A prática de manutenção desses cultivares pelos chamados guardiões das sementes é parte constitutiva do modo de vida do camponês sertanejo que vive no semiárido. Só em Apodi, foram 12 Casas de Sementes com cerca de 200 famílias. A iniciativa acabou inspirando a criação do Plano Estadual de Sementes Crioulas.

O esforço de adaptação constitui um componente estratégico da noção de convivência com o semiárido e uma expressão clara da reconexão das dimensões culturais, produtivas e simbólicas que envolvem a produção agrícola. Como mostra o trabalho de Santos (2016) não são apenas as sementes que são resgatadas, mas as pessoas e seus modos de vida. A manutenção da sociobiodiversidade e da agrobiodiversidade se coloca como uma questão-chave na reconexão orientada pelos referenciais da agroecologia.

Outra ação importante nesse processo é a Política de Um Milhão de Cisternas (P1MC). A ideia foi construir um milhão de cisternas em todo o semiárido para armazenar água da chuva e garantir o abastecimento das populações das áreas rurais nos períodos de estiagem. A P1MC recebeu diversos prêmios internacionais pela sua capacidade inovadora de democratização do acesso à água junto das populações vulneráveis e pela sua metodologia participativa (Santos; Rozendo; Diniz, 2019). Estudos apontaram os impactos na saúde, com a diminuição de doenças de veiculação hídrica principalmente em crianças, como a diarreia (Santana et al., 2012). Na ausência das chuvas, a água estocada, mesmo que por carro-pipa, permitiu manter pequenos plantios garantindo a reprodução de sementes crioulas justamente quando uma das piores secas da história da região semiárida (de 2010 a 2017) comprometeu gravemente os estoques.

O fortalecimento da cadeia produtiva do mel é apontado como um grande propulsor do debate sobre a agroecologia em Apodi. O entendimento de que as abelhas eram incompatíveis com os ambientes degradados estimulou a adesão a sistemas produtivos mais sustentáveis. Além disso, o 
acesso ao PRONAF permitiu investimentos em unidades de beneficiamento do mel e na constituição das cooperativas que passaram a comercializar o produto em maior escala via exportação e mercados institucionais, como o Programa de Aquisição de Alimentos (PAA) e o Programa Nacional de Alimentação Escolar (PNAE).

A consolidação de novos canais de comercialização foram fundamentais na reconexão entre produção, beneficiamento e consumo. Além da feira local, o PAA e o PNAE foram importantes catalisadores e potencializadores das iniciativas agroecológicas (Rozendo, 2017; Santos, 2016; Dias et al., 2013). A garantia da comercialização de modo regular e a preço justo promoveu a ampliação e a diversificação da produção com repercussões importantes para a segurança alimentar, tanto para aqueles que ofertavam os produtos quanto para os que recebiam (público contemplado pela política de assistência social). No PAA e no PNAE, previa-se um acréscimo de 30\% no valor em caso de aquisição de produtos agroecológicos e/ou orgânicos, incentivo que veio a fortalecer as experiências já em curso no território.

O papel desses programas na construção de vínculos entre os diferentes elos da cadeia de alimentos é destacado como um fator de relevância na promoção da agricultura familiar, em especial em bases ecológicas (Santos, 2016; Dias et al., 2013). Apesar disso, tanto o PAA como o PNAE vêm sendo duramente ameaçados por mudanças nos controles sanitários e pelo seu enfraquecimento no atual governo de Jair Bolsonaro. Desde 2011, os sistemas de inspeção usuais (formados por técnicos do município) passaram a não ser mais aceitos, dificultando a produção de polpa de frutas, mel, carne e derivados do leite, desestimulando a produção. Vale destacar que, embora muitos projetos agroecológicos fossem implementados a partir das ações do hoje extinto Ministério do Desenvolvimento Agrário, as regras de controle de conformidade sempre estiveram sob a responsabilidade do Ministério da Agricultura, Produção e Abastecimento (MAPA), órgão alinhado ideologicamente ao setor do agronegócio. Em razão disso, o PAA, em 2015, foi praticamente paralisado, comprometendo a produção agroecológica em Apodi com inúmeras repercussões para a agricultura familiar, o que também acabou motivando a busca por uma certificação dos produtos orgânicos.

No ano de 2013, outra ação do governo federal viria a ameaçar os sistemas produtivos agroecológicos da Chapada do Apodi. Foi dado início a um projeto de fruticultura irrigada no local onde viviam cerca de 6 mil agricultores familiares. A proposta previa inclusive a remoção de muitas famílias assentadas pelos programas de reforma agrária, justamente onde existiam muitas iniciativas agroecológicas (Filho; Lunes, 2018). O projeto encontra-se atualmente paralisado, mas as obras iniciais já desviaram e represaram as águas do rio, inviabilizando a produção agroecológica em algumas comunidades. Apesar do projeto do perímetro irrigado ter perdido força, várias empresas de fruticultura de menor porte se estabeleceram em Apodi, comprometendo, no seu conjunto, o 
abastecimento de água e a produção das áreas de agricultura familiar, num processo claro de desconexão.

\section{ASSENTAMENTO DO CONTESTADO/LAPA}

O Assentamento Contestado está localizado no município da Lapa, a 70km de Curitiba no Estado do Paraná. É uma área que originalmente foi doada pelo governo português, no período colonial, em 1740, ao Barão dos Campos Gerais (Família Costa), que se estabeleceu no local fundando a Fazenda Santa Amélia. Em 1985, a fazenda foi adquirida pela Cerâmica Incepa. No entanto, em razão de dívidas fiscais da empresa, o governo federal entrou com um processo de desapropriação da fazenda para fins de reforma agrária, atendendo à reivindicação do Movimento dos Trabalhadores Rurais Sem Terra. Em função da morosidade do processo, o MST ocupou a área em 1999, com 40 famílias visando a acelerar a desapropriação. Mediado pelo Incra, o assentamento foi finalmente criado em 2001, contando com 108 famílias. Atualmente, o assentamento é ocupado por 120 famílias, distribuídas em lotes que variam de 10 a 16 hectares e organizados em 10 núcleos (Costa, 2018; Garrido, 2019). O assentamento compreende uma extensão de 3.228 hectares, sendo 1.240 hectares de proteção ambiental (Valadão, 2011).

No assentamento, os assentados recriam uma forma camponesa de produzir e viver, em conformidade com o que os sociólogos rurais denominam de recampesinização (Wanderley, 2009; Ploeg, 2008). Esse processo de recriação de um novo camponês segue um movimento global, incluindo os países de modernidade avançada como a França, onde o camponês constitui mais uma identidade política e cultural. A Via Campesina, como movimento internacional, do qual o MST faz parte, é articuladora dessa reconstrução político-identitária.

No assentamento da Lapa, os camponeses, em sua grande maioria filhos de camponeses tradicionais, são oriundos de várias regiões do Paraná, incluindo municípios da Região do Sul do Paraná, onde se localiza o assentamento. De seus locais de origem, herdaram uma prática que combina agricultura e criação de animais, uma experiência que inclui afazeres relacionados a processos de uma indústria artesanal, hábitos de lazer e formas comunitárias de relação social.

Trajetória das políticas e potencialização da agroecologia

No início da organização do assentamento, praticaram uma agricultura convencional, e muitos deles cultivavam grãos como soja e milho, seguindo uma tendência de uma agricultura modernoindustrial. A partir de 2002, a direção geral do assentamento, assim como a do MST, passou a preconizar uma agricultura ecológica. Essa orientação seguiu a diretriz do MST, que, a partir do seu 
IV Congresso Nacional, propôs um novo modelo de reforma agrária baseado em uma agricultura livre de transgênicos, centrado na agroecologia e meio ambiente. No Estado do Paraná, um movimento ainda mais forte pela disseminação da agricultura ecológica foi organizado pelas Jornadas de Agroecologia, cujo primeiro evento foi organizado em 2002, na cidade de Ponta Grossa. Na sequência, a jornada foi organizada na região de Cascavel, seguindo para Francisco Beltrão, Londrina, Maringá, Irati, Lapa e finalmente para Curitiba, a capital do Estado. No encontro da Lapa, líderes do assentamento do Contestado assumem o protagonismo na organização da jornada junto a atores locais, como a Prefeitura da Lapa, o Instituto Agronômico do Paraná (IAPAR), o Centro Paranaense de Referência em Agroecologia (CPRA), a Rede Ecovida de Agroecologia, professores, pesquisadores e técnicos e militantes ecológicos. Devemos destacar que uma das oficinas de troca de experiências agroecológicas desse evento foi realizada no Assentamento da Lapa. Nessa oportunidade, os assentados trocaram experiências com os camponeses, os agricultores familiares, os pesquisadores e os interessados em práticas agroecológicas.

Ao mesmo tempo que o Movimento dos Sem Terra e a Rede Ecovida de Agroecologia (no Sul do Brasil) promoveram a agroecologia entre os camponeses, os agricultores familiares e os assentados, políticas institucionais de fomento à agroecologia e à agricultura orgânica foram formuladas no âmbito do governo federal. A ecologização do Assentamento do Contestado se desenvolveu em um contexto já institucionalizado da agroecologia, cujas políticas possibilitaram financiamentos, apoio à infraestrutura, dinamizando a atividade entre os agricultores e, especificamente nesse caso, junto aos assentamentos. Desse modo, em 2003, a Lei $\mathrm{n}^{\mathrm{o}} 10.831$ regularizou o consumo de ecológicos mediante a certificação da produção agroecológica. Mais tarde, em 2007, o Decreto-Lei $n^{\circ} 6323$ reconheceu as diferentes correntes agroecológicas, o que sem dúvida foi um passo importante para o movimento agroecológico e para as "ecologias emergentes", embora todos tenham permanecido sob a rubrica da agricultura orgânica ${ }^{7}$. No Assentamento do Contestado, além de se praticar a agroecologia e a agricultura orgânica, emergiram ecologias fruto de um hibridismo de práticas e saberes, conforme será visto mais adiante.

Por fim, entre os diversos decretos relacionados à agroecologia, vale ressaltar o Plano Nacional de Agroecologia e Agricultura Orgânica (PLANAPO), instituído pelo decreto $\mathrm{n}^{\mathrm{o}} 7794$, em 20 de agosto de 2012, que teve por objetivo articular diferentes políticas ou ações que induziram à produção ecológica. O plano se mostrou fundamental para a transição ecológica no assentamento, juntamente com o Programa de Aquisição de Alimentos (PAA) e o Programa Nacional de Alimentação Escolar (PNAE) (Valadão, 2011), uma vez que potencializou ações e práticas que já vinham sendo propostas pelo MST, bem como por outras redes sociotécnicas. Desse modo, foi

\footnotetext{
${ }^{7}$ A agricultura orgânica é apenas uma das modalidades de agricultura ecológica. O selo geral deveria trazer a rubrica agricultura ecológica. Venceu, todavia, o apelo dos grupos de produtores mercantis já estabelecidos.
} 
possível consolidar uma infraestrutura de suporte ao mercado institucional (PAA e PNAE). A Cooperativa Terra Livre, criada em 2010 pelo MST local, foi fundamental. Além de organizar a entrega da produção do PAA e PNAE, também articulou outros circuitos de venda local, de entrega residencial, de feiras e de mercado local (Valadão, 2011). Dessa forma, as políticas públicas (PAA, PNAE, PLANAPO) corroboraram as diretrizes do MST, os fóruns e os encontros de agroecologia, e estimularam práticas ecológicas no âmbito dos lotes dos agricultores, potencializando a transição ecológica na perspectiva técnica, social e econômica. Essa sinergia no primeiro momento assegurou sobrevivência e renda para os agricultores (Valadão, 2012) mediante a diversificação da agricultura e a construção de circuitos curtos de comercialização. O mercado promoveu o cultivo de hortaliças e de grãos diversos em função da demanda de um consumidor que também se instituia como consumidor ou ator ecológico que diversifica seu cardápio alimentar. Assim, se de um lado ocorreu uma demanda diversificada, de outro se expandiu a quantidade de produtos cultivados - em torno de 134 (Vasco, 2018), incluindo variedades até então pouco comercializadas, como a mandioca, a batatadoce, o inhame, o amendoim, o mel e produtos processados artesanalmente, como queijo, geleias, compotas, etc. Revalorizou-se um conjunto de produtos cultivados tradicionalmente, os quais acabaram retornando à categoria de produtos "portfólios de ofertas" nos circuitos locais de comercialização, tal como já foi estudado por Piraux e Cuenin (2019).

A agroecologia na reconexão entre agricultura, meio ambiente, alimentação e saúde

O Assentamento da Lapa constitui referência para a transição ecológica no âmbito do MST. Nesse caso, a conversão das práticas agrícolas convencionais para práticas ecológicas assume importância central na reconexão entre agricultura, ambiente e alimentação e saúde. Das 120 famílias assentadas, 56 praticam agroecologia em maior ou menor grau (Silva, 2018). Esse assentamento se constitui como um dos 35 assentamentos no Estado do Paraná que seguem a política geral do MST de ecologizar a agricultura. A conversão para agricultura ecológica começou com nove famílias, depois foi ampliada para 15, avançou para 32 e assim sucessivamente (Valadão, 2011). Esse processo de mudança, contudo, não ocorreu sem conflitos. A disputa entre os chamados "veneneiros" e os “orgânicos" continua até hoje, mas no jogo de interesses prevaleceu o dos ecológicos, que são os assentados que mais participam do movimento organizado (Silva, 2018; Vasco, 2018; Valadão, 2011).

A força do movimento foi, sem dúvida, um fator importante na definição da forma de fazer agricultura e de reconstruir um estilo, ou modo de vida, em consonância com a nova condição camponesa. Quando surgiram lotes vagos, foram os interessados na agroecologia que tinham preferência (Valadão, 2011). No entanto, a decisão de ecologizar a produção não é uma questão fácil 
para os assentados, sobretudo em um contexto em que, antes de mais nada, está em jogo a sobrevivência de suas famílias. Embora possamos afirmar que os filhos de camponeses, ou novos camponeses, tragam uma experiência de uma agricultura que mobiliza recursos e insumos produtivos naturais, era a agricultura especializada, da monocultura, que sustentava, bem ou mal, suas condições de vida. Além do mais, muitos deles desconheciam as condições ecológicas locais relacionadas à vocação da agricultura (Vasco, 2018). É por isso que políticas como o PAA e o PNAE, na medida em que demandam alimentos ecológicos, exercem um papel central no processo de conversão da agricultura e na sustentação das condições de vida. Foi o PAA, segundo os agricultores do assentamento, que possibilitou essa mudança. Conforme um agricultor citado no estudo de Valadão, "Seis ou sete anos antes do PAA não havia perspectiva para a agroecologia" (Valadão, 2011, p. 112). A importância do PAA na potencialização da ecologia se deve à formação de um mercado institucional que trouxe segurança para os assentados na comercialização dos produtos agroecológicos (Silva, 2018).

Por um lado, se o PAA, assim como o PNAE, impulsiona o processo de ecologização, ele reformula, por outro, a paisagem da agricultura, que passa a ser mais diversificada por conta de uma demanda de mercado. Todos os assentados ecológicos diversificam a produção. No total, o PAA comercializa 34 produtos ecológicos certificados, mas também convencionais (49), principalmente hortícolas. No âmbito da organização da produção, cada família cultiva entre 11 a 23 espécies ${ }^{8}$ (Valadão, 2011, p. 163), dentre elas, dez para comercialização, em média. No conjunto, os assentados produzem 134 itens, sendo 86 hortaliças, 30 frutas e 17 tipos de grãos (Vasco, 2018). Em razão das políticas institucionais, 96,4\% dos assentados produzem hortaliças. Ao mesmo tempo que se diversifica a produção para o mercado, produz-se para o autoconsumo, restabelecendo a produção de alimentos para a família e reforçando a política de segurança alimentar (Silva, 2018; Valadão, 2011, p. 165). A produção para a alimentação da família abrange outros produtos, além daqueles orientados para o mercado, tais como suínos, aves e produção de leite. Assim, 84\% das famílias criam suínos, $50 \%$ criam aves, e $60 \%$ produzem leite, tudo produzido para o abastecimento familiar. Entre os assentados ecológicos, 95\% produzem para o autoconsumo (Silva, 2018). A mudança no padrão produtivo interfere no padrão alimentar, que é tido como fator importante de manutenção de saúde.

A esse respeito, foi a saúde que mais motivou os assentados a produzirem ecologicamente. Entre outros fatores, como renda, sustento da família, curiosidade, 50,9\% citaram a saúde como um dos motivos para aderirem à agroecologia (Vasco, 2018). A razão disso pode ser encontrada nos vários exemplos de intoxicação por uso de agroquímicos. Todos mencionaram algum tipo de doença atribuída ao uso dos agrotóxicos antes de eles, os assentados, se tornarem ecológicos. Problemas de

\footnotetext{
${ }^{8}$ Culturas agrícolas mais comuns: milho, alface, repolho, beterraba, mandioca, batata-doce, abobrinha, couve, cheiroverde, abóbora, almeirão, cenoura (Valadão, 2011).
} 
saúde que foram mencionados pelos assentados: depressão, infecção, problemas de estômago, câncer, etc. (Vasco, 2018). A saúde, segundo a percepção da maioria dos assentados, pode ser interpretada como uma noção polissêmica, isto é, envolve diversas dimensões relacionadas com a alimentação, com o cuidado relativo ao viver bem, mas também com o ambiente natural. Entre os recursos que compõem o ambiente natural, a terra merece destaque. A razão para essa preocupação pode ser encontrada no significado que a terra exerce na reprodução do campesinato, conforme demonstrado por estudos clássicos, entre eles "O afeto da terra" de Carlos Brandão (1999). A terra é o substrato da natureza, um patrimônio natural que requer cuidados e atenção à sua linguagem: "a terra fala", segundo uma assentada citada por Vasco (2018, p.172). "Nós podemos ver que a terra é a saúde e da saúde dela é que vem a nossa saúde né? Se nós não cuidar da terra como que nós vamo ter nossa saúde?", diz outra assentada (Vasco, 2018 p. 173).

Assim como a terra, outros componentes da natureza requerem cuidados, pois a saúde do homem depende da saúde da natureza. Essa reconexão com o mundo natural se explicita mediante diversas formas de sentimentos e cuidados. Se a natureza forma esse pano de fundo a partir do qual se compreende o que seja ambiente saudável para a saúde dos camponeses, a questão alimentar é aquela que mais diretamente diz respeito, razão pela qual a produção de alimentos naturais, sem agroquímicos, retorna com força.

Juntamente com a produção de alimentos, os camponeses cultivam ervas medicinais, para o tratamento de doenças. Entre os camponeses que produzem para o autoconsumo, $73 \%$ plantam ervas medicinais (Vasco, 2018). O tratamento de doenças, à base de ervas, contudo, não é feito isoladamente. Ele é acompanhado de outras práticas de diferentes matrizes culturais e que são reinventadas no assentamento. A primeira das práticas, que antecede a qualquer tipo de tratamento, conhecida praticamente por todos os assentados, é a bioenergia. Mediante a bioenergia, é realizada uma espécie de diagnóstico de equilíbrio energético. Esse diagnóstico revela qual a fragilidade do corpo, ou qual órgão do organismo humano está fragilizado, indicando assim o tipo de tratamento que será necessário. Considerando-se o fluxo energético, recorre-se então a ervas medicinais, à alimentação, à auricultura, ao benzimento ou simultaneamente a diversas medidas (Vasco, 2018).

A mescla de conhecimentos a que os assentados recorrem para tratamento da saúde não se restringe às práticas alternativas. No assentamento, há uma unidade de saúde, instalada pela prefeitura local, onde agentes de saúde atendem semanalmente. Neste posto de saúde, atendem o médico, consultores de bioenergia, benzedeiras, entre outros agentes orientadores de práticas alternativas. É nesse sentido que se pode afirmar que os conhecimentos de várias matrizes se interligam e formam uma rede complexa de complementariedade e de diálogo de saberes (Leff, 2001). O conhecimento tradicional, no qual as benzedeiras e parteiras têm papel importante, é revalorizado no sistema de saúde local. Nesse sistema híbrido de conhecimentos, a natureza ocupa um lugar determinante. O 
alimento natural, que muitas vezes é considerado como remédio, é em sua maioria tido como preventivo, por isso manter a natureza equilibrada ou cuidada é também manter o equilíbrio do organismo humano. Cuidar da natureza e da alimentação é cuidar da saúde: "Decidimos plantar o orgânico por causa da saúde...", diz um assentado"; "Se nois quiser ter saúde, temos que produzir do jeito da natureza", diz outra agricultora (Vasco, 2018, p. 173).

Produzir alimentos de acordo com os ciclos e as leis da natureza é cuidar da saúde e é o pressuposto-chave da agroecologia, que, potencializada pelas políticas sociais, promove a reconexão com o mundo natural. Esse ambiente natural, mediado por relações de produção de uma agricultura diversificada, é construído por um sistema híbrido de conhecimento que redefine a atividade agrícola não apenas enquanto atividade técnica, mas também enquanto cultura. Na perspectiva do "novo camponês", uma agricultura diversificada, voltada para a produção de alimentos e o sustento da família, é também uma estratégia de reconstrução da autonomia, um valor caro ao ethos do camponês clássico e que se expressa na recampesinização do assentado.

\section{O CASO DE ARDECHE}

\section{Características do território}

Ardèche meridional, localizado no Sul da França (departamento de Ardeche), é um território rural esparso que alterna áreas de vales, terraços e montanhas geralmente cultivados, sendo mesclado por pequenas cidades, dentre as quais Aubenas, a mais importante, representa uma população de cerca de 55 mil habitantes, considerando os 130 mil do território como um todo. Após um longo período de êxodo rural, a região tem passado por uma renovação demográfica desde os anos 1990.

Este território tem uma imagem muito "alternativa" e é frequentemente associado à figura de "neorrurais" - a região, desde os anos 1970, foi terra de acolhida do movimento de regresso à terra (Rouvière, 2015). Na verdade, muitos neorrurais integraram-se localmente, participando fortemente da vida social, cultural e econômica dos vilarejos e, por vezes, desenvolvendo iniciativas coletivas, muitas vezes em conjunto com os agricultores locais. No geral, este território possui uma agricultura bastante diversificada e ecológica (em torno de 25\% de agricultura orgânica), com propriedades razoavelmente pequenas, em média, ainda que também seja uma área de agricultura bastante especializada ou mesmo intensiva. De 1950 à década de 1980, foi uma grande área de fruticultura. No início dos anos 1990, a produção local perdeu a sua competitividade e começou a declinar continuamente (Lamine et al., 2015). A substituição pela produção de uva tende agora a gerar uma dinâmica de (re)especialização agrícola em determinados setores, mesmo se no geral a agricultura 
permanece diversificada. Em termos sociais, é um território com um nível de pobreza superior à média e, portanto, com fortes desafios de inclusão social.

Trajetória e antecedentes

A análise das principais políticas públicas nos diferentes níveis de intervenção e das principais iniciativas no sistema agroalimentar territorial permitiu construir uma periodização da trajetória passada em quatro grandes períodos, desde meados do século XIX, com um trabalho mais aprofundado nas últimas quatro décadas trazendo maiores pontos de inflexão ${ }^{9}$.

Até as décadas de 1950-1960, o sistema agroalimentar territorial era diversificado, orientado principalmente para um mercado local e relativamente ecologizado, com uma forte conexão e interdependência entre agricultores e consumidores locais. Da década de 1960 ao início da década de 1990, época de ouro do movimento de especialização e intensificação da arboricultura, o sistema agroalimentar foi cada vez mais "puxado" pela distribuição em massa a jusante e com um duplo movimento de padronização e diferenciação (com muitas formas de valorização da qualidade e origem da produção). Nesse contexto, os atores intermediários de distribuição, coleta e processamento desempenharam um papel fundamental. Entre meados da década de 1990 e de 2010, assistimos à consolidação dos processos de qualificação, à afirmação da questão da multifuncionalidade e à proliferação de iniciativas agroalimentares. Neste período, em que se disseminaram as iniciativas em torno da alimentação de qualidade e de localidade, fortemente apoiadas em políticas territoriais, assistimos à afirmação de duas dinâmicas mais ou menos interligadas.

Por um lado, em torno da Câmara de Agricultura, principal organização de extensão rural do departamento, e de estruturas satélites, muitas iniciativas têm sido desenvolvidas com o objetivo de promover os produtos locais e viabilizar a economia agroalimentar local: indicações geográficas que visam a valorizar produtos específicos (vinho, castanhas, queijo de cabra etc.); a marca Goûtez l'Ardèche, criada em 1994, que também valoriza produtos mais comuns, distribuídos nos diversos circuitos de comercialização (supermercados, lojas turísticas, restaurantes locais); lojas de produtores instaladas pela cooperativa frutícola local a partir de 2008, com vistas à diversificação ligada ao contexto de crise da fruticultura.

Por outro lado, as redes "alternativas" de desenvolvimento rural e de agricultura camponesa e/ou orgânica, por sua vez, desenvolveram, a partir de meados da década de 1990, um conjunto de iniciativas de natureza diferente: lojas coletivas de produtores, Amap (Associations de Maintien de

\footnotetext{
${ }^{9}$ A esse respeito, favor consultar: $<\underline{\text { https: } / / \text { www.assiette-territoire.com/trajectoire }>}$. 
L'agriculture Paysanne), circuitos de distribuição de produtos orgânicos adaptados às novas formas de abastecimento (drive-in, internet, etc.), uma operação (De Ferme en Ferme) lançada desde 1999 pelo Civam (organização de agricultura alternativa e desenvolvimento local) que organiza passeios de visitas às propriedades locais para os habitantes, etc. Diversas associações que atuam na área de educação ambiental, juventude e integração social desenvolveram, ao longo do tempo, iniciativas sobre esses temas. Aos poucos, foram se estabelecendo alianças entre essas diversas redes locais (agricultura alternativa, desenvolvimento rural, economia social e solidária, educação). Assim, foi criada, em 2009, uma rede de educação ambiental e de desenvolvimento sustentável, chamada Pétale 07, que reúne cerca de 60 estruturas educativas e/ou associativas. Eles defendem uma visão ecológica e solidária da transição agrícola e alimentar e realizam inúmeros cursos de formação, ações sociais e eventos.

As instituições públicas territoriais aparecem como atores-chave, em razão do apoio estruturante que prestam a essas várias iniciativas e dinâmicas. As políticas públicas territoriais apoiam financeiramente a maioria dos projetos e setores associados a iniciativas de valorização da qualidade (caso da marca Goûtez l'Ardèche e do setor da castanha, por exemplo). As iniciativas de redes alternativas também são apoiadas por políticas públicas territoriais ou por financiamentos europeus (por exemplo, o programa Leader de Développement Rural). Muitas são financiadas por fundações ou editais de projetos, que tendem a aumentar nos últimos tempos, fragilizando a continuidade das ações.

Por volta de 2015, assistimos ao desenhar de uma virada com o surgimento da problemática ambiental e climática (sendo a Cop21 um dos marcadores desta virada) e das questões de saúde e inclusão social, o que marca o quarto período da trajetória. Por um lado, certas políticas territoriais foram reorientadas e o financiamento regional, em particular em um contexto de mudança da maioria regional, tornou cada vez mais difícil o acesso a redes alternativas, o que conduz ao encerramento de muitas iniciativas inovadoras e a um fenômeno de dispersão. Por outro lado, as políticas nacionais e o novo dispositivo implementaram os Projetos Territoriais Alimentares (PAT), criado em 2014, e estimularam os atores locais a considerar os projetos "sistêmicos", visando, justamente, a articular agricultura, alimentação, meio ambiente e saúde ${ }^{10}$.

As questões de ecologização e saúde estão implícitas na noção de “qualidade alimentar" e na menção da agricultura orgânica, mesmo que essas duas questões permaneçam em segundo plano em relação à questão da relocalização e da reconexão entre a agricultura e a alimentação. No território

\footnotetext{
${ }^{10}$ Os PATs "cumprem o objetivo de [...] implementar um sistema alimentar territorial”, "participam na consolidação de setores territorializados e no desenvolvimento do consumo de produtos de curto-circuito, em particular relativos à produção orgânica", "visam a reaproximar produtores, processadores, distribuidores, coletivos territoriais e consumidores e desenvolver a agricultura nos territórios e a qualidade dos alimentos" (LOAAF de 13 de outubro de 2014, Art. L 111$2-2)$.
} 
de Ardèche Méridionale, um primeiro projeto PAT foi construído em 2016, pelos atores agrícolas convencionais da primeira rede (Câmara de agricultura, organizações com a marca "Goutez l'Ardèche", e o "Pays" correspondem ao território de l'Ardeche Méridionale). Seu título, “Alimentação e desenvolvimento territorial", tal como os argumentos utilizados, exprime a prioridade atribuída à questão da economia e do desenvolvimento local. O projeto exclui uma diversidade de atores potencialmente envolvidos nas redes alternativas mencionadas acima, o que conduz a fortes críticas externas. A reconexão entre agricultura, alimentação, meio ambiente, saúde e justiça social parece fraca neste primeiro projeto, uma vez que sua narrativa e suas ações centraram-se principalmente na rotulagem de produtos locais e na identificação de propriedades agrícolas. Posteriormente, em 2021, outro projeto PAT foi montado por um conjunto de municípios em menor escala, que visa a associar, de forma mais ampla, as várias redes de atores mobilizados. Os temas da saúde e da justiça social estão mais presentes nesse segundo projeto com uma diversidade de ações, e, nesta última fase, as políticas públicas desempenham um papel de "potencialização" mais próximo do que tem sido observado no primeiro PAT e nos casos brasileiros. Esse projeto, no entanto, diz respeito apenas a uma parte do território, enquanto outras partes, menos equipadas com as competências e recursos para montar um projeto, ficam fora desta dinâmica.

Configuração das relações entre redes de atores e narrativas

A análise realizada da trajetória do sistema agroalimentar territorial, resumida acima, mostra a presença de duas redes de atores portadores, relativamente desarticulados, com os quais as instituições públicas estabeleceram alianças e, sobretudo, relações de apoio (e de financiamento). Essas duas redes de atores (a primeira ligada aos atores agrícolas convencionais e focada na valorização dos produtos, a segunda ligadas aos atores da agricultura alternativa, do desenvolvimento rural, da economia social e solidária e da educação), que iniciam uma variedade de iniciativas concretas, têm visões, prioridades e narrativas diferentes. A análise dessas narrativas e do conteúdo concreto das iniciativas, através da análise da trajetória, permite compreender quais são os desafios da reconexão entre agricultura, alimentação, meio ambiente, saúde e justiça social, e como as políticas públicas apoiam ou não um determinado tipo de iniciativa e, portanto, o desafio de reconexão.

A narrativa veiculada pela rede focada na valorização dos produtos não coloca os aspectos ambientais e de saúde em primeiro plano, e essas são pouco articuladas como questão-chave para reconectar a agricultura e os alimentos.

Na narrativa das redes alternativas, o desafio da reconexão entre agricultura, alimentação e meio ambiente está muito presente, em ligação com a inclusão social e com a saúde, que se afirma de modo crescente no período recente. Por exemplo, são desenvolvidos cursos "de cozinha nutritiva" 
(cozinha nutritiva, com base em alimentos locais e receitas saudáveis) para cozinheiros da merenda escolar. Também são implementados projetos que visam a aproximar agricultores e populações carentes em torno das questões de alimentação saudável e inclusiva, apoiados pela constituição de uma rede de agricultores que atua em diversos estabelecimentos sociais ou de ensino, ou, ainda, projetos sociais e sistemas de cestas de hortaliças "solidárias", de preços baixos para os consumidores pobres.

As alianças entre as instituições públicas e essas diferentes redes se reconfiguram, portanto, fortemente ao longo do tempo, com um acesso ao financiamento público que permanece mais difícil para as redes alternativas do que para os atores agrícolas mais estabelecidos, mesmo que as ações das primeiras estejam ganhando legitimidade e reconhecimento. Ao contrário dos casos brasileiros, com os programas PAA/PNAE ou Cisternas e ATER em agroecologia, políticas públicas "genéricas" que apoiem a reconexão entre agricultura, alimentação, meio ambiente e saúde, parecem mais limitadas: a política agroecológica lançada em 2012 teve um forte impacto político, mas efeitos limitados. A lei recente sobre a alimentação (lei Egalim) deverá ter efeitos mais consistentes no campo da merenda escolar (questão a ser estudada no futuro). O apoio do governo aos PATs fica com um financiamento limitado e funciona por chamadas que favorecem territórios que dispõem das competências dos recursos para montar projetos. As iniciativas que reivindicam essa reconexão permanecem a maior parte do tempo submissas à temporalidade e ao enquadramento de chamadas de projetos que fragilizam a sua perenização.

\section{OS CASOS EM DISCUSSÃO}

Os casos estudados, embora sejam distintos em relação à história e à organização de seus territórios, apresentam pontos em comum. No que se refere aos antecedentes históricos, seus territórios são fortemente marcados por uma organização socioprodutiva camponesa ou familiar que expressa o resultado de movimentos de retorno à terra, ou de luta pelo acesso à terra: como nos casos dos neorrurais em Ardèche e da recampesinização, via assentamentos rurais, em Apodi e na Lapa. São territórios fortemente marcados por projetos e ações diferenciadas e contemplados por políticas de inclusão social, em que agroecologia ocupa lugar central na construção dos sistemas agroalimentares alternativos, apesar da força da agricultura convencional. Configura-se assim uma rede de múltiplos atores do qual participam instituições públicas e agências governamentais e não governamentais. No caso específico do Brasil, as políticas de combate à pobreza e de transição ecológica, principalmente nos governos recentes de Lula e Dilma, fizeram diferença na promoção da agroecologia em Apodi e na Lapa. 
O papel dos movimentos sociais na transição agroecológica territorial

Nos três casos estudados, as propostas de movimentos sociais e de organizações locais foram decisivas para implementar a agroecologia, ou atividades de cunho ecológicas. No caso de Apodi, as ações promovidas pelo MAB, na organização do Sindicato dos Trabalhadores Rurais, fariam deste movimento um ator importante na organização de um dos primeiros projetos: a organização das casas de sementes que viriam a recuperar espécies tradicionais da produção de alimentos, reconectando agricultura e alimentação, mas também os saberes associados a ela. O mesmo se observa no caso da Lapa, onde o MST estabelece diretrizes para a produção agroecológica e organiza as Jornadas da Agroecologia que incitam os assentados a converter seus sistemas agroalimentares. Em Ardèche, várias organizações locais participam ativamente na formulação de projetos alternativos ligados à agricultura biológica e/ou camponesa. Há, desta forma, um “capital social” que, ao ser considerado pelas políticas públicas, encontra terreno fértil para o fortalecimento da agroecologia e desencadeia ações que assumem um caráter sinérgico na sua promoção, que permitem reconexão em vários níveis: do agricultor com seu território, do agricultor com os cultivos tradicionais e com os mercados locais.

O papel da ação pública na potencialização da transição agroecológica

À proposta de atores locais, mais políticas públicas aliam-se enquanto força política, ou melhor, enquanto ecopolítica ${ }^{11}$, na medida em que os interesses de organizações encontram respaldo nas instâncias organizativas do poder. No Brasil, são os movimentos sociais que vão pautar, no âmbito dos poderes governamentais, em diferentes níveis, a política de agroecologia, de fomento e de mercados institucionais. No caso de Ardèche, o Projeto Alimentar Territorial, iniciado pelos atores públicos, tenta incluir nas ações de atores alternativos e dos atores agrícolas "convencionais" uma visão comum.

As ações públicas são diversas e podem ser identificadas segundo sua especificidade territorial, como as Unidades Demonstrativas de Manejo da Caatinga, Hortas e Pomares Agroecológicas, Projeto Bioágua, Casa de Sementes, Políticas de Cisternas, fortalecimento da cadeia produtiva do mel (Apodi); Diretrizes do MST e Projeto Jornadas de Agroecologia (Lapa); Projetos Alimentares Territoriais (Ardèche).

Dessa forma, as ações coletivas provenientes de organizações e movimentos sociais que se conjugam com políticas públicas mais gerais formam o que denominamos ação pública, que, em

\footnotetext{
${ }^{11} \mathrm{Na}$ perspectiva do pensamento da ecologia política. 
função de sua sinergia, desencadeia uma força potencializadora na transição agroecológica, conforme constatado nos casos analisados, dos sistemas agroalimentares nos territórios.

Fatores facilitadores da ecologização

Atuam como facilitadores da transição ecológica diversos fatores, conforme a singularidade do território. O primeiro fator a ser considerado é o saber tradicional, fruto da herança de uma experiência camponesa. O território de Apodi é marcado por um campesinato tradicional, mesmo entre os novos assentamentos. Esse também é o caso da Lapa, onde egressos do movimento de luta pela terra se instalaram no território e construíram uma infraestrutura local, ligada ao conhecimento ecológico. Em Ardèche, a figura do camponês é reinventada pelos neorrurais e também pelos agricultores mais jovens de origem local, que participam de programas de agricultura alternativa, de educação ambiental e de acesso à alimentação. Outro fator que contribui para a ecologização dos territórios são as organizações sociais e as redes de atores locais estabelecidas. Foram construídas cooperativas, postos de vendas, escolas locais, centros de arte e lazer, que permitem o desenvolvimento de uma cultura cujas questões locais e ecológicas são valorizadas. Essas organizações tanto contribuem com a formulação de propostas, como desenvolvem uma educação social e ecológica, criando um sentimento de pertencimento local.

Inserem-se nessa perspectiva os cursos ofertados para treinamento dos camponeses e agricultores familiares, como é o caso da Lapa e de Apodi (cursos de manejo da caatinga, de hortas, técnico em agroecologia, processamento de polpas de frutas). As jornadas de agroecologia, com as oficinas ecológicas, a Rede de Educação e Meio Ambiente em Ardèche, que traz uma perspectiva solidária e ecológica, constituem um sistema de aprendizagem e de diálogo de saberes que propiciam reconstruir um conhecimento e práticas da agroecologia. Embora não possam ser generalizadas em todos os casos aqui apresentados, essas atividades fazem com que os territórios se apresentem como referência em agroecologia, assumindo uma perspectiva de desenvolvimento sustentado de maneira social e ecológica.

\section{CONSIDERAÇÕES FINAIS}

A agroecologia, como força mobilizadora de ações individuais e coletivas, mediante as diversas propostas políticas e iniciativas locais, acima citadas, desempenha um papel articulador entre a agricultura, a alimentação, o meio ambiente e a saúde, em diferentes graus e em conformidade com a natureza do território. De início, o que fica mais evidente nos casos é a conexão entre a agricultura e a produção de alimentos, nos âmbitos dos territórios, além de uma conexão direta de grupos de 
agricultores com grupo de consumidores. De um lado, a agroecologia, como forma de produzir, recuperou variedades locais que haviam desaparecido da pauta de consumo alimentar. De outro, os mercados institucionais provocaram, mediante a necessidade de ofertas de alimentos, a diversificação dos sistemas produtivos, restabelecendo a segurança alimentar entre produtores e consumidores. Essa mudança de paradigma para uma agricultura diversificada, em relação à exploração de uma agricultura convencional especializada, mais especificamente nos casos brasileiros, restabeleceu a autonomia dos camponeses em relação à produção para o autoconsumo. Nos três casos, a reconexão com o meio ambiente resultou da mudança de paradigma para a agroecologia (sob diversas formas, incluindo a agricultura biológica). O caso mais relevante é a mudança de paradigma proposta pela Convivência com o Semiárido. A partir da Política de Cisternas, constituiu-se a base para a recuperação de um ambiente capaz de reproduzir a vida biológica e social dos camponeses. A reconexão com a saúde ficou mais implícita no caso francês em função da qualidade dos alimentos. Mais recentemente, emergiram projetos focados sobre essa reconexão. No caso da Lapa, há programas específicos, como o de saúde comunitária, que alia tratamentos alternativos de cunho ecológico com a medicina convencional. A proposta de plantio de ervas medicinais vai nesse sentido. A saúde é vista pelos assentados de uma forma mais ampla que a saúde corporal dos assentados: tratase de manter saudável o ambiente de modo geral, o que configura um modo ecológico de viver. Em Apodi, a Política de Cisternas evidencia uma conexão mais direta com a saúde, na medida que os estudos mostram a diminuição de doenças de veiculação hídrica.

Os três casos analisados ilustram, de formas distintas, graus diferenciados de reconexão entre agricultura, alimentação, meio ambiente e saúde. Esta reconexão apoia-se na agroecologia, que é potencializada por iniciativas locais e pela implementação de políticas públicas.

\section{REFERENCIAS BIBLIOGRÁFICAS}

ARAÚJO, R. M. de. Programa de Aquisição de Alimentos (2003-2010): Avaliação da implementação pela CONAB no Rio Grande do Norte. 2012. 336 f. Tese (Doutorado) - Curso de Administração, Universidade Federal do Rio Grande do Norte, Natal, 2012.

BRANDÃO, C. R. O afeto da terra. Campinas: EDUNICAMP, 1999.

BRASIL, MDS (2015) Relatórios de informações Sociais. Disponível em http://aplicacoes.mds.gov.br/sagi/RIv3/geral/index.php Acesso em: 28/05/2015.

COSTA E SILVA, L. da. As racionalidades da agricultura agroecológica na gestão de seus estabelecimentos: um estudo no Assentamento Contestado - Lapa/PR. 2018. Tese (doutorado) Universidade Federal do Paraná, Curitiba, 2018. 
DIAS, T. F.; NUNES, E. M.; TORRES, F. L.; TORRES, A. C. M. O Programa de Aquisição de Alimentos da Agricultura Familiar (PAA) como estratégia de inserção socioeconômica: $\mathrm{O}$ caso do Território da Cidadania Sertão do Apodi (RN). Revista Brasileira de Gestão e Desenvolvimento Regional, Taubaté, v. 9, n. 3, p.100-129, 2013. Disponível em: $<$ https://doi.org/10.54399/rbgdr.v9i3.1127>. Acesso em: 10 abril 2021.

FILHO, J. L. de O. P ; LUNES, A. R. da S. O perímetro irrigado na chapada do Apodi-Rn: Surgimento, descrição e governança. - Anais XVIII ENANPUR, 2019. Disponível em: $<$ http://anpur.org.br/xviiienanpur/anaisadmin/capapdf.php?reqid=712>. Acesso em: 10 abril 2021.

GOODMAN, D. Espaço e lugar nas redes alimentares alternativas: conectando produção e consumo. In: Schneider, S.; Gazolla, M. (org.). Cadeias curtas e redes agroalimentares alternativas: negócios e mercados da agricultura familiar. Porto Alegre: Editora da UFRGS, 2017, p.259-280.

GURGEL, R. F. de S. Agricultura familiar e assessoria técnica: uma análise da experiência do projeto Dom Helder Câmara no território sertão do Apodi/Rn. Dissertação apresentada à Universidade Federal Rural do Semi-Árido - UFERSA no Programa em Ambiente, Tecnologia e Sociedade, 2016.

IBGE. Censo Demográfico 2010. Disponível em: <http://www.censo2010.ibge.gov.br>. Acesso em: 14 de agosto de 2014.

IBGE. Censo agropecuário 2006. Rio de Janeiro: Ministério do Planejamento, Orçamento e Gestão, 2006. 267 p.

IPEA. Atlas do desenvolvimento humano do Brasil, 2013. Disponível em:

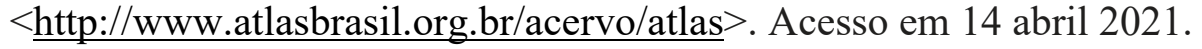

LAMINE, C; BUI, C; OLLIVIER, G. Pour une approche systémique et pragmatique de la transition ecologique des systèmes agri-alimentaire. In: Cahier de Recherches Sociologiques n,58. Montréal: Éditions Athéna, 2015.

LEFF, E. Saber ambiental: sustentabilidade, racionalidade, complexidade, poder. Petrópolis: Vozes, 2001.

MDA. Ministério do Desenvolvimento Agrário. Plano de Desenvolvimento Territorial do Alto Sertão do Apodi. Disponível em: <http://sit.mda.gov.br/download/ptdrs/ptdrs qua territorio032.pdf $>$. Acesso em: 10 mar. 2021.

MDA. Ministério do Desenvolvimento Agrário. Território da Cidadania Açu/Mossoró (RN) Célula de Acompanhamento e Informação (CAI). Disponível em: $<$ http://sit.mda.gov.br/download/ra/ra001.pdf.> Acesso em: 05 abril 2021.

MOTTA, E. G.R. O sentido do tempo livre para os camponeses do Assentamento do ContestadoLapa/PR. Curitiba, 2019. (Tese de doutorado) Universidade Federal do Paraná, 2019.

NUNES, E M; SCHNEIDER, S. Reestruturação Agrícola, Instituições e Desenvolvimento Rural no Nordeste: A Diversificação da Agricultura Familiar do Pólo Açu-Mossoró(RN). Revista Econômica do Nordeste. Fortaleza, v. 44, n. 3, p. 601-626, jul-set. 2013. Disponível: $<$ https://www.bnb.gov.br/revista/index.php/ren/issue/view/26 $>$. Acesso em 13 ago. 2020.

PIRAUX, M.; CUENIN, P. J. C. M. Evolução das conexões entre produção e consumo e seus impactos sobre as dinâmicas de um território: o caso de Mocajuba na Amazônia Oriental-PA. Redes 
(Santa Cruz do Sul Online), v. 24, n. 3, p. 101- 117, 2019. Disponível em: $<$ https://doi.org/10.17058/redes.v24i3.14120>. Acesso em: 10 abril 2021.

PLOEG, J. D. Van der. Mercantilização da agricultura e desenvolvimento territorial. In:SCHNEIDER, S. A diversidade da agricultura familiar. Porto Alegre: EDUFRGS, 2006.

PLOEG, J. D. Van der. Os Camponeses e Impérios Agroalimentares: lutas por autonomia e sustentabilidade na era da globalização. Porto Alegre: Editora da UFRGS, 2008.

RENTING, H.; MARSDEN, T.; BANKS, J. Compreendendo as redes alimentares alternativas: o papel de cadeias curtas de abastecimento de alimentos no desenvolvimento rural. In: Gazolla, M. Schneider, S. Cadeias curtas e redes agroalimentares alternativas: negócios e mercados da agricultura familiar. Porto Alegre: Editora da UFRGS, 2017. p. 27-51

ROZENDO, C. Limites e possibilidades dos circuitos curtos enquanto estratégia de desenvolvimento: O caso do Programa de Aquisição de Alimentos em APODI -RN- In: Anais do Encontro Anual da ANPOCS. 2017.

ROZENDO, C. Os (des)caminhos do Programa de Aquisição de Alimentos na região semiárida: novas governanças, antigas armadilhas. In: (org) PEREZ-CASSARINO, J. P; TRICHES, R.. Abastecimento alimentar: redes alternativas e mercados institucionais. 1ed. Chapeco: Editora da UFFS, 2018, v. 1, p. 203-234.

SANTANA, V. L.; ARSKY, I. da C.; SOARES, C. C. S. (2012). Democratização do acesso à água e desenvolvimento local: a experiência do Programa Cisternas no semiárido brasileiro. IN: Anais do Circuito de Debates Acadêmicos: programa e resumos. - Brasília: Ipea. Disponível em: $<$ http://www.ipea.gov.br/code2011/chamada2011/pdf/area7/area7-artigo34.pdf $>$. Acesso em: 19 Set. 2019.

SANTOS, C. F.; ROZENDO, C; DINIZ, P. C. O. Você tem sede de Quê? Os Programas de Cisternas no Semiárido Potiguar Brasileiro como Dispositivos de Desenvolvimento In: IX Encontro da ANPPAS, 2019, Brasília. Anais do IX Encontro Nacional da Pós-Graduação em Ambiente e Sociedade, 2019. p.2112 - 2141.

SANTOS, Boaventura S. A gramática do tempo: para uma nova cultura política. São Paulo: Cortez Editora, 2006.

VALADÃO, A. C. Transição ecológica nos assentamentos rurais: estratégias de resistências e produção de novidades. 2011. Tese (doutorado) - Universidade Federal do Paraná, Curitiba, 2011.

VASCO, A. P.D. Inovações Socioambientais em uma experiência de agricultura familiar ecológica na Região Metropolitana de Curitiba (RMC): Espaço de reprodução e modo de vida. 2018. (Tese de doutorado) Universidade Federal do Paraná, Curitiba, 2018.

VENDRUSCOLO, R., MATTE, A.; VENTURA, F.; TOURRAND, J.; WAQUIL, P. Entre a reconexão e a revalorização: a constituição de convenções em mercados da agricultura familiar no Brasil, na Itália e na França. Estudos sociedade e agricultura, v. 26 n 3, p. 495-516, 2018. Disponível: $<$ https://doi.org/10.36920/esa-v26n3-1>. Acesso em 13 ago. 2020.

VIEIRA, D. D. O espaço rural como construção social: agentes políticos e instituições no processo de relações da agricultura familiar. In: (Orgs). ROZENDO, C.; BASTOS, F.; PAIVA, I. Dossiê rural - dinâmicas contemporâneas no mundo rural. Cronos: Revista de Pós-Graduação em Ciências Sociais. UFRN, Natal, v. 14, n.2, p.53 - 73 jul./dez. 2013. 
WANDERLEY, M. de N. B. Agricultura. Raízes históricas do campesinato brasileiro. IN: WANDERLEY, M. de N. B. O Mundo rural como espaço de vida: reflexões sobre a propriedade da terra, agricultura familiar e ruralidade. Porto Alegre: UFRGS, 2009. 